\title{
Functional Mechanisms and Roles of Adaptor Proteins in Abl-Regulated Cytoskeletal Actin Dynamics
}

\author{
Mizuho Sato, ${ }^{1,2}$ Masahiro Maruoka, ${ }^{1,3}$ and Tatsuo Takeya ${ }^{1}$ \\ ${ }^{1}$ Graduate School of Biological Sciences, Nara Institute of Science and Technology, 8916-5 Takayama, Ikoma, Nara 630-0192, Japan \\ ${ }^{2}$ Institute of Microbial Diseases, Osaka University, Osaka 565-0871, Japan \\ ${ }^{3}$ Laboratory of Single-Molecule Cell Biology, Tohoku University Graduate School of Life Sciences, Aoba-ku, Sendai, \\ Miyagi 980-8578, Japan \\ Correspondence should be addressed to Tatsuo Takeya, ttakeya@bs.naist.jp
}

Received 16 February 2012; Accepted 16 March 2012

Academic Editor: A. Yoshimura

Copyright ( 2012 Mizuho Sato et al. This is an open access article distributed under the Creative Commons Attribution License, which permits unrestricted use, distribution, and reproduction in any medium, provided the original work is properly cited.

\begin{abstract}
$\mathrm{Abl}$ is a nonreceptor tyrosine kinase and plays an essential role in the modeling and remodeling of F-actin by transducing extracellular signals. Abl and its paralog, Arg, are unique among the tyrosine kinase family in that they contain an unusual extended C-terminal half consisting of multiple functional domains. This structural characteristic may underlie the role of Abl as a mediator of upstream signals to downstream signaling machineries involved in actin dynamics. Indeed, a group of SH3containing accessory proteins, or adaptor proteins, have been identified that bind to a proline-rich domain of the C-terminal portion of $\mathrm{Abl}$ and modulate its kinase activity, substrate recognition, and intracellular localization. Moreover, the existence of signaling cascade and biological outcomes unique to each adaptor protein has been demonstrated. In this paper, we summarize functional roles and mechanisms of adaptor proteins in Abl-regulated actin dynamics, mainly focusing on a family of adaptor proteins, Abi. The mechanism of Abl's activation and downstream signaling mediated by Abi is described in comparison with those by another adaptor protein, Crk.
\end{abstract}

\section{Introduction}

The filamentous (F)-actin cytoskeleton is a fundamental component of all eukaryotic cells and plays an integral role in determining cell shape and locomotion. Thus, F-actin dynamics must be regulated strictly in a spatiotemporal manner for proper biological output. This is achieved through functional interaction with other cytoskeletal components, intermediate filaments (IFs) and microtubules (MTs), and hundreds of accessory proteins. Signaling factors that stimulate F-actin rearrangement such as extracellular matrices (ECMs) and growth factors are known to cause an increase in Abl tyrosine kinase activity, followed by the relocalization of Abl to specific F-actin structures such as focal adhesion sites, lamellipodia, and membrane ruffles depending on the stimulus $[1,2]$, implying a role for $\mathrm{Abl}$ in actin-based processes under the influence of upstream signals as well as downstream signaling machineries. Indeed, when the expression of $\mathrm{Abl}$ is downregulated or even the
Abl kinase activity is suppressed, the dynamism of F-actinbased processes becomes impaired [3]. Therefore, tyrosine phosphorylation of specific substrates and the formation of actin cytoskeleton-remodeling protein complexes through $\mathrm{Abl}$ appear essential to the rapid and dynamic regulation of the assembly as well as disassembly of F-actin [4-7].

How can Abl be involved in such diverse aspects of actin dynamics? Primary as well as higher structural features may underlie such functional properties. Indeed, the overall domain structure of the Abl kinases is unique among the tyrosine kinase family $[5,6]$. First, structural and biochemical analyses have revealed that multiple autoinhibitory mechanisms arise from interactions within the N-terminal domain structure [8-12]. The formation and disruption of this structure play a key role in the regulation of the kinase activity of Abl. Next, the Abl protein is also unique in that the kinase domain is followed by an unusual extended carboxyl (C)-terminal region which consists of multiple functional domains including an actin-binding region and 


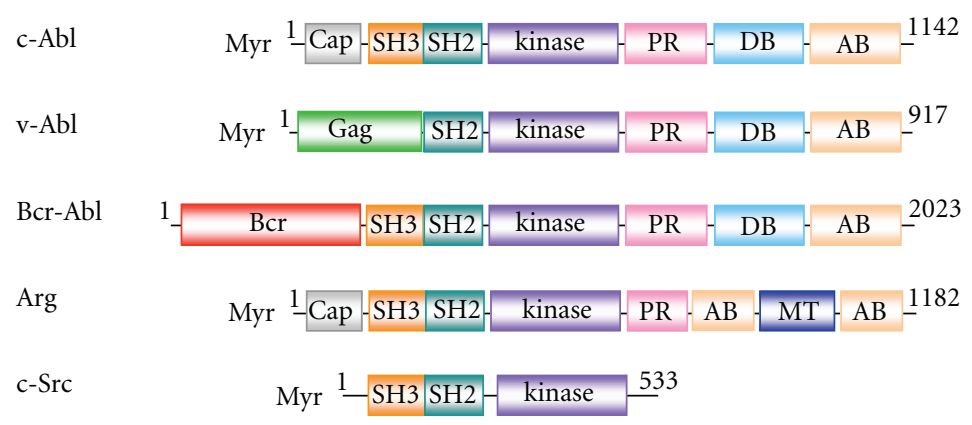

Figure 1: Primary structure of Abl kinases. Only isoform $1 \mathrm{~b}$ of c-Abl and Arg in mice is shown. Both have a "Cap" region at the extreme $\mathrm{N}$-terminus (Cap, gray), followed by the Src homology-3 domain (SH3, orange), Src homology-2 domain (SH2, blue-green), and catalytic domain (kinase, purple). However, at the extreme N-terminus, v-Abl contains a viral "Gag" sequence (Gag, green) by replacing the "Cap" and the $\mathrm{SH}$, and Bcr-Abl contains the N-terminal portion of the Bcr protein (Bcr, magenta) by replacing the "Cap," which were generated by uptake into a retrovirus and chromosomal translocation, respectively. In the C-terminal half, Abl has four P-x-x-P motifs and Arg has three in the proline-rich region (PR, pink). At the extreme C-terminus, there are actin-binding domains in Abl and Arg (AB, beige). In addition, Abl has a DNA-binding region (DB, light blue), while Arg has a microtubule-binding domain (MT, blue). Amino acid residues of each gene in mice are numbered except for the human P210 Bcr-Abl gene [42]. The primary structure of c-Src is shown for comparison [43].

so can directly create and respond to cytoskeletal changes that affect cell shape and movement [5]. Moreover, recent studies have revealed the functional role of adaptor proteins in regulation of the kinase activity and substrate recognition of Abl through the interaction with specific motifs in this portion, and the existence of the distinctive signaling cascade unique to each member in these processes also became evident, as described below $[5,6]$.

In this paper, we first introduce structural and functional characteristics of $\mathrm{Abl}$, summarize the outline of Abl-mediated F-actin signaling cascades, and subsequently describe the roles and functional modes of an adaptor protein, Abi, in the process of Abl-mediated actin dynamics, in comparison with those of another adaptor protein, Crk.

\section{Abl Tyrosine Kinase Family}

2.1. Origin and Physiological Roles. The Abl gene was first isolated as a transforming gene in the Abelson murine leukemia virus (A-MuLV) [13], whose product, v-Abl, showed tyrosine kinase activity [14], and was subsequently determined to be an altered form of the cellular Abl gene $(\mathrm{c}-a b l)$ [15]. In addition to the activation mechanism through incorporation into A-MuLV, a reciprocal $\mathrm{t}(9 ; 22)(\mathrm{q} 34 ; \mathrm{q} 11)$ chromosomal translocation generates a chimeric Bcr-Abl protein, with elevated kinase activity, which has been frequently observed in chronic myeloid leukemia (CML) and adult acute lymphoblastic leukemia (ALL) patients [16, 17]. An Abl-related gene (or arg) is a paralog of c-abl identified by sequence similarity [18]. In addition to vertebrates, Abl-family genes have been found in Drosophila melanogaster ( $\mathrm{dAbl}$ ) and Caenorhabditis elegans $(A B L-1)[19,20]$.

$\mathrm{Abl}$ and Arg seem to have substantial functional overlap in vivo. Mice with a disrupted c-abl show defective development $[21,22]$ and responsiveness of $B$ cells $[23,24]$ and $\mathrm{T}$ cells [25]. Some of the surviving $\mathrm{c}-a b l-/-$ mice were reported to show osteoporosis, decreased systolic blood pressure, and cardiac hyperplasia [21, 22, 26]. In contrast, Arg's ablation leads only to relatively subtle neuronal defects [27]. The c-abl-/- arg-/- double mutation, however, causes embryonic death with abnormalities in neuroepithelial cells and defects in neurulation [27]. In addition, dysregulation of Abl leads to several pathological states; recent evidence suggests possible roles of Abl in breast-cancer invasiveness [28], neurological disorders [27], and microbial pathogenesis $[29,30]$.

2.2. Primary Structure and Functional Domains. The overall domain structure of each Abl family protein is shown in Figure 1. The SH3, SH2, and kinase domains of c-Abl share only $52 \%$ identity, with $37 \%$ identity in the $\mathrm{SH} 3$ and $\mathrm{SH} 2$ domains, when compared to another nonreceptor tyrosine kinase, Src [6]. The "Cap" and SH3 domains are replaced with the viral "Gag" sequence in v-Abl [14], while the $\mathrm{Abl}$ breakpoint position in Bcr-Abl consistently leads to removal of the "Cap" sequence but retention of the SH3 domain [16]. In the C-terminal half, Abl and Arg contain proline- $x-x-$ proline (P-x-x-P: $x$, any amino acid) motifs in the proline-rich region (PR) which allows interactions with $\mathrm{SH} 3$ domain-containing proteins and a calponin homology $(\mathrm{CH})$ domain at its extreme C-terminus that binds to both $\mathrm{F}$ and globular (G)-actin [31-33]. However, there is only 29\% sequence identity between $\mathrm{Abl}$ and $\mathrm{Arg}$ in the C-terminal half [18], implying unique functions in each gene. Indeed, $\mathrm{Abl}$ contains a DNA-binding region $[34,35]$, nuclear localization signal motifs [35], and a nuclear export signal [36], allowing it to shuttle between the nucleus and cytosol [37]. Nuclear Abl plays a role in transcriptional regulation, particularly in response to DNA damage [38], and activation of the nuclear pool of Abl can induce apoptosis [39]. Cytoplasmic Abl, on the other hand, becomes localized to dynamic regions of the cytoskeleton including membrane ruffles, leading edges, and F-actin protrusions in response to extracellular stimuli such as growth factors like EGF and PDGF and cell adhesion [1, 7, 40]. The oncogenic Bcr-Abl and v-Abl proteins, however, 


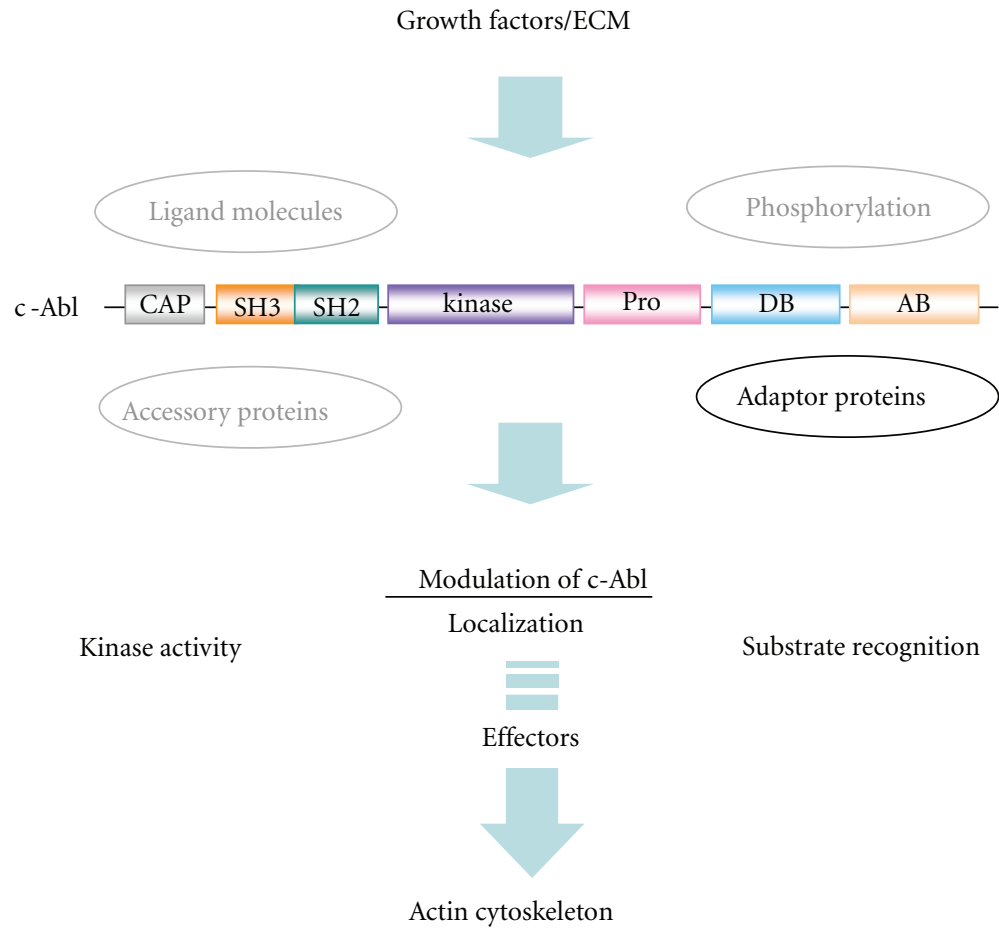

Figure 2: Signaling upstream and downstream of Abl leading to actin dynamics. Abl kinase activity, localization, and substrate phosphorylation which are responsible for F-actin dynamics may be modulated by ligand molecules, accessory proteins, phosphorylation by other kinases, and/or adaptor proteins as described in the text. However, the role of adaptor proteins is mainly highlighted in this paper. ECM: extracellular matrix.

do not enter the nucleus despite the presence of the nuclear localization signals [41].

\section{Regulatory Mechanism of Abl Kinase Activity}

Abl kinase activity is regulated in a variety of ways reflecting its domain structure, and this regulation may confer on Abl its role as a mediator of signaling in actin dynamics [4] (Figure 2). First, structural data and biochemical studies have revealed multiple autoinhibitory mechanisms that constrain the enzymatic activity. The N-terminal half consisting of the "Cap", SH3, SH2, and kinase domains (residues 1-531 in $\mathrm{c}-\mathrm{Abl}$ ) represents the minimum segment for this autoregulation [8] in which interaction made by its $\mathrm{SH} 3$ and $\mathrm{SH} 2$ domains with the distal surface of the kinase domain imposes a "locked" inactive state $[8,9,44-46]$. Attachment of a myristoyl group to the $\mathrm{N}$-terminus or phosphorylation in the "Cap" sequence further stabilizes this inactive conformation through additional surface interaction $[8,9]$. Consequently, disruption of such structural hindrances leads to an increase in kinase activity as observed in $\mathrm{v}-\mathrm{Abl}$ and $\mathrm{Bcr}-\mathrm{Abl}$ (Figure 2). Release of the latch and clamp can also be achieved by binding of either the intracellular domain of activated integrins or $\mathrm{P}-\mathrm{x}-\mathrm{x}-\mathrm{P}$ and/or phosphotyrosine-containing ligands to the $\mathrm{SH} 3$ and $\mathrm{SH} 2$ domains $[5,45]$. Indeed, when fibroblasts were plated on fibronectin or treated with an $\alpha 5$ integrin cross-linking antibody, increased Abl kinase activity was observed [39]. However, full activation of c-Abl kinase activity requires the phosphorylation of both Y245 and Y412
[47-50]. Y245 resides between P242 and P249, which are responsible for the intramolecular interaction with the $\mathrm{SH} 3$ domain. The phosphorylation of Y245 can be achieved by the Src family kinases or autophosphorylation reaction in trans $[48,51]$ and is presumed to activate Abl kinase through the disruption of this intramolecular interaction, as has been observed in the P242E/P249E mutant [52]. Y412, on the other hand, is located in the activation loop of the kinase domain and conserved in all tyrosine kinases. Y412 has been identified as an autophosphorylation site accompanied by the elevation of intrinsic kinase activity and is presumed to be responsible for the binding of substrate $[1,6]$. Indeed, such phosphorylated forms have been identified in the Bcr$\mathrm{Abl}$ and $\mathrm{v}$-Abl proteins $[51,53]$.

The importance of the C-terminal half in the regulation of Abl has been clarified in various studies [31-33]. For example, c-Abl mutant mice lacking the $\mathrm{C}$-terminal portion but retaining the $\mathrm{SH} 3, \mathrm{SH}$, and kinase domains exhibit the same phenotype as $c$-abl knockout mice [22]. Moreover, adaptor proteins consisting of multi-SH3 domains have been identified to interact with the $\mathrm{PR}$ region of the $\mathrm{C}$ terminus in Abl/Arg (Table 1). Also, the binding of F-actin to the AB region could contribute by inhibiting the kinase activity [54]. Catalytic activity, on the other hand, is required for c-Abl to modulate the F-actin cytoskeleton, suggesting that there could be a bidirectional regulatory mechanism between $\mathrm{Abl}$ and $\mathrm{F}$-actin in the process of $\mathrm{F}$-actin recognition and modulation [4]. A contribution of the phosphorylation of Tyr and Ser residues in this region has also been proposed [6]. 
TABLE 1: Adaptor proteins for c-Abl in mice.

\begin{tabular}{lcc}
\hline Adaptor protein & Target domain in Abl & References \\
\hline c-Crk: CrkI, CrkII & Proline-rich motif & {$[55-57]$} \\
CrkL & Proline-rich motif & {$[58]$} \\
Abi1/E3B1 & Proline-rich motif/SH3 & {$[59-61]$} \\
Abi2/ArgBP1 & Proline-rich motif/SH3 & {$[62,63]$} \\
CAP/Ponsin/SH3P12 & Proline-rich motif & {$[64,65]$} \\
Vinexin & Proline-rich motif & {$[67]$} \\
Nck & Proline-rich motif & {$[68]$} \\
Cbl & Proline-rich motif & {$[63]$} \\
ArgBP2/Sorbs2 & Proline-rich motif & \\
\hline
\end{tabular}

Adaptor proteins that bind Abl and function in Abl-mediated signaling in mouse cells are listed together with the target domain in Abl.

\section{Regulation of Abl Kinase by Abi and Crk}

4.1. Abi and Crk Families. Nine proteins have been identified in mice that bind the $\mathrm{C}$-terminal half of $\mathrm{Abl}$ and function as adaptors (Table 1). Among them, the Abi and Crk families are known to be phosphorylated by $\mathrm{Abl}$ and, in turn, modulate Abl. Consequently, clarification of the mode of interaction between $\mathrm{Abi} / \mathrm{Crk}$ and $\mathrm{Abl}$ has been a subject of intensive research in this field $[59,69,70]$.

The Abi family proteins, Abi1 and Abi2, were originally identified as proteins that bind to the $\mathrm{P}-\mathrm{x}-\mathrm{x}-\mathrm{P}$ motif in $\mathrm{Abl}$ and negatively modulate its transforming activity [62, 77]. A third member, Abi3, was identified as a new gene in humans, NESH, possessing an SH3 domain, and was later incorporated into the Abi family on the basis of amino acid sequence similarity [78]. However, its binding to Abl has not been identified. Features of the primary structure of the Abi family are illustrated in Figure 3(a) [55-57, 71-76]; a proline-rich region and $\mathrm{SH} 3$ domain are common. c-Crk, on the other hand, is the cellular homolog of $\mathrm{v}$-Crk which was isolated as a transforming gene of the CT10 retrovirus [55]. c-Crk is expressed as two distinct proteins, CrkI and CrkII, respectively, by an alternative splicing of c-crk mRNA [56, 57]. CrkI consists of one $\mathrm{SH} 2$ and one $\mathrm{SH} 3$ domain, while CrkII has an additional SH3 domain separated by a "spacer region" of approximately 60 amino acids: SH3 (N) and SH3 (C) (Figure 3(a)). The Crk SH2 domain shows affinity for the binding motif $\mathrm{pY}-\mathrm{x}-\mathrm{x}-\mathrm{P}$. Indeed, multiple motifs are present in prominent Crk SH2-binding proteins such as p130Cas and paxillin $[69,76]$. A paralog of Crk, Crk-like (CrkL), has been identified [58]. CrkL also consists of one SH2 and two SH3 domains without any catalytic domain (Figure 3(a)) and interacts with the proline-rich region. Roles of CrkL have been mostly characterized in Bcr-Abl-positive cells [76, 79].

Abil-null mice die in the midgestational stage and show phenotypes similar to those of $\alpha 4$ integrin or VCAM1 knockout mice, implying that Abil could be a key mediator of $\alpha 4$-mediated signaling at the leading edge [80, 81]. Abi1 was actually found to interact and colocalize at the leading edge of lamellipodia with phosphorylated $\alpha 4$, and deletion of Abil dramatically diminishes spreading of fibroblasts engineered to express $\alpha 4$ on both VCAM1 and fibronectin [81]. Mice lacking Abi2 showed abnormal phenotypes in the eye and brain [82]. On the other hand, Crk knockout mice exhibited marked growth retardation with poorly developed a heart and vasculature and died in utero [83]. These results imply distinctive roles for Abi1, Abi2, and Crk in vivo.

4.2. Regulatory Mechanism of Abl Kinase by Abi and Crk. Abi1 and Abi2 play a dual role as potential effectors and regulators of the Abl kinase [70, 84]. Abl is known to oligomerize through the $\mathrm{N}$-terminal region (509 residues) depending on its kinase activity, and Abil also oligomerizes and an oligomeric form of Abil interacts with the Abl protein [85]. How the phosphorylation of Abi by $\mathrm{Abl}$ and/or autophosphorylation of Abl play roles in these steps remains to be elucidated. Regarding this, several tyrosine phosphorylation sites have been identified in Abi1 [86-90]. Among them, Y213 [89] and Y398 [90] were reported to play a role in the regulation of Abl (Figure 4(a)). Regarding this, preferred Abl target sites have been identified as I/V/L- $-\mathrm{X}_{1-5}$ $\mathrm{P} / \mathrm{F}$ using an mRNA display method [91]. When compared, the flanking amino acid sequences of Y213 (D-Y-M-T-S-P) lacks an upstream hydrophobic residue, whereas Y398 (IY-D-Y-T-K-D-K) lacks a downstream proline/phenylalanine residue [92]. Phosphorylation of Y213 was reported to be involved in the binding to the $\mathrm{Abl} \mathrm{SH} 2$ domain and consequently induce downregulation of its catalytic activity [89]. Phosphorylated Y213 was also shown to interact with the p85 C-terminal SH2 domain and negatively regulate p85dependent macropinocytosis [93]. However, the interaction of a phosphopeptide with the $\mathrm{SH} 2$ domain induces a conformational change in $\mathrm{Abl}$, increasing the kinase activity $[45,94]$. Furthermore, phosphorylation of Y213 in Abil is seen in several Bcr-Abl-transformed leukemic cell lines [60]. Therefore, the significance of Y213 in the regulation of Abl awaits further clarification. Y398 in the SH3 domain of Abi1, on the other hand, was recently identified as another major site of phosphorylation by Abl [90]. Y398, located in the RT-loop of the SH3 domain, is highly conserved among other SH3 domain-containing proteins and presumed to play a role in the binding of target peptides [95]. Indeed, the $\mathrm{SH} 3$ domain of Abil and the proline-rich domain of Abl were identified as responsible for the interaction between Abil and Abl, leading to the activation of $\mathrm{Abl}$ kinase, whereas disruption of Y398, combined with Y213, 
Abi

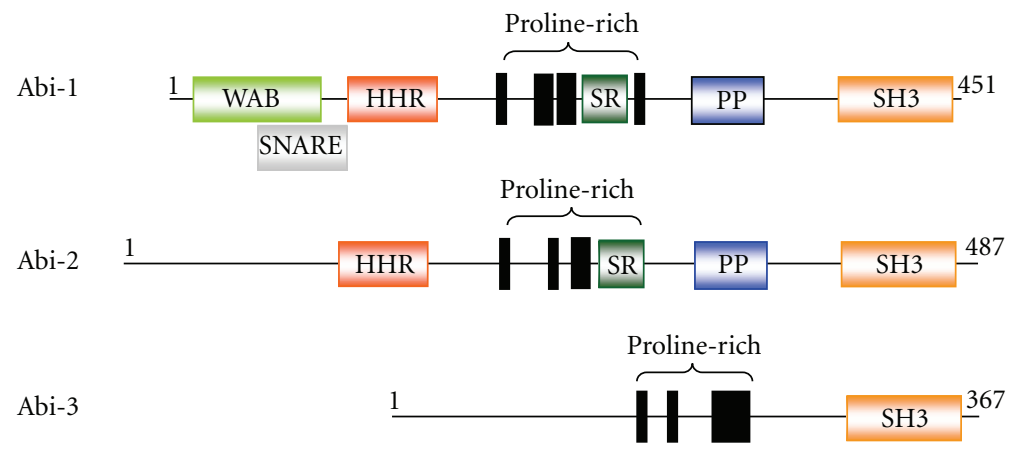

Crk

Crkl

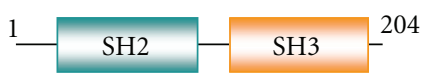

CrkII

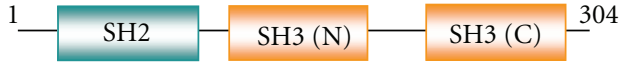

CrkL

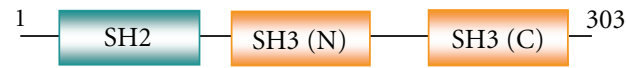

(a)

Abil

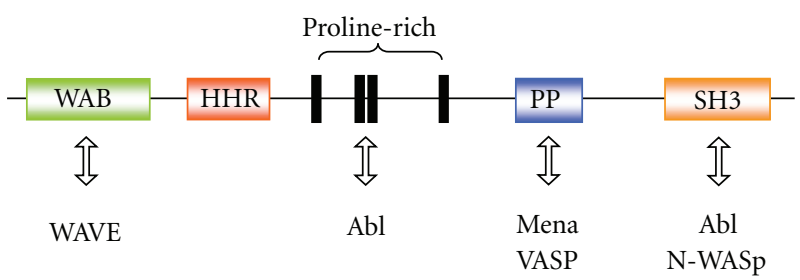

CrkII

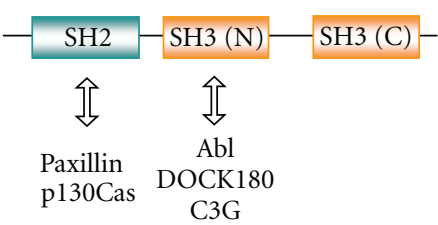

(b)

Figure 3: Domain structure of the Abi and Crk family proteins. (a) Modular domains of the Abi and Crk family proteins in mice are illustrated. For the Abi family, WAB (light green): WAVE-binding domain, SNARE (grey): Syntax-1 binding domain which is an overlapping domain of WAB, HHR (red): Hox homology region, SR: serine/threonine-rich region, PP (cyan): polyproline structure, SH3 (orange): SH3 domain [55, 71-75]. For the Crk family, SH2 (blue-green): SH2 domain, SH3 (orange): SH3 (N) and SH (C) domains [56, 57, 76]. Amino acid residues in each protein are numbered; only isoform 1 for Abi2 and Abi3 is shown. (b) Proteins reported to interact with Abil and CrkII involved in the regulation of Abl-mediated actin dynamics are shown. 
c-Abl/Abi-1
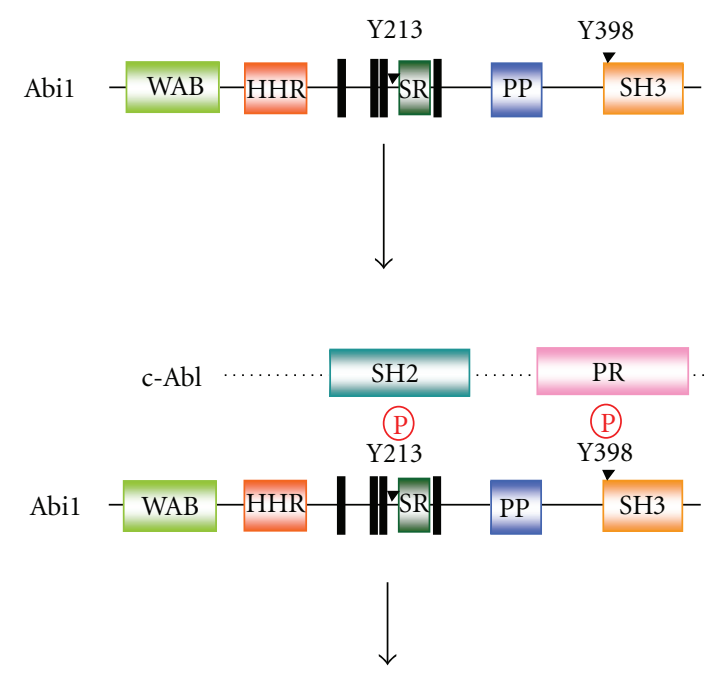

Activation of Abl kinase
c-Abl/Abi-2
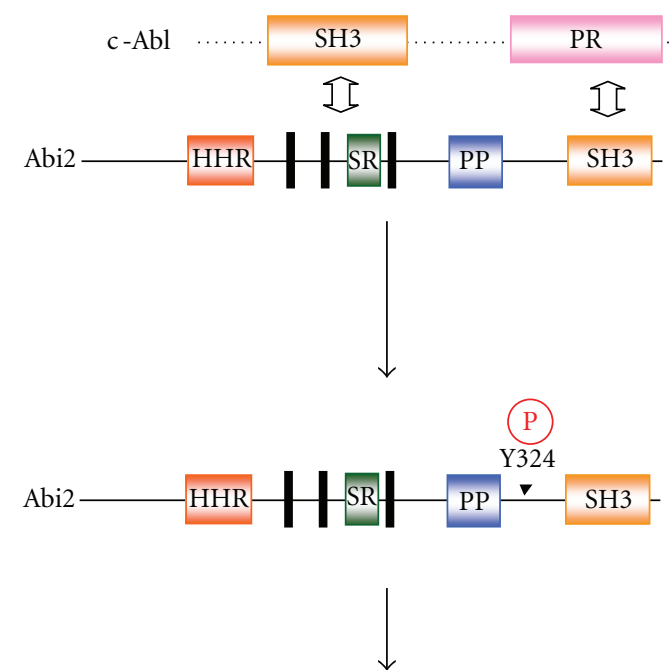

Activation of Abl kinase

(a)

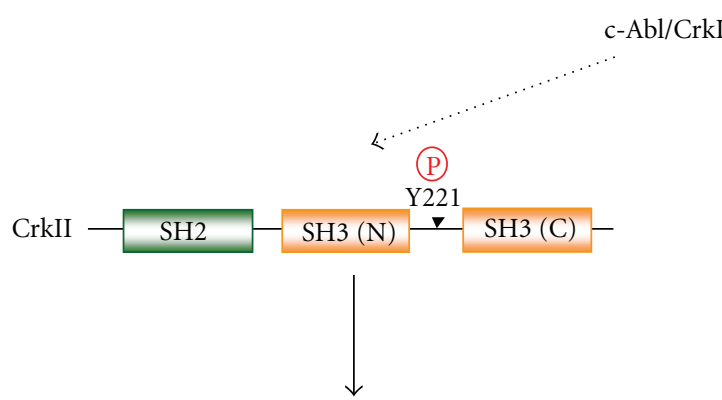

Formation of intramolecular SH2-pTyr clamp

Suppression of Abl kinase activation<smiles>C1CCCCC1</smiles>

Disassembly of Crk-signaling complex
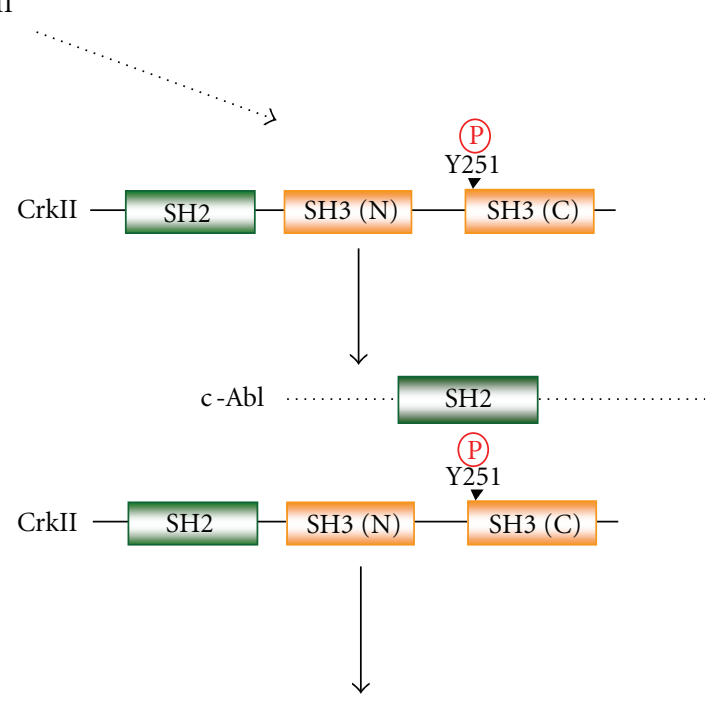

Release of the latch and clamp of c-Abl

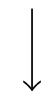

Activation of Abl kinase

(b)

FIGURE 4: Regulatory mechanism of Abl kinase activity by Abi and Crk. (a) Events leading to the activation of the Abl kinase activity after the interaction of Abl and Abi1 or Abi2 are schematically illustrated. The regulatory Y213 and Y398 in Abi1 and Y324 in Abi2 are indicated. Phosphorylated Y213 and Y398 in Abil are involved in the interaction with c-Abl through the SH2 and PR region of c-Abl, respectively. (b) Y221 and Y251 in CrkII are sites of phosphorylation by Abl after the interaction of Abl and CrkII. When Y221 is phosphorylated, it induces an "autoinhibition" through an intramolecular SH2-pTyr clamp and the suppression of Abl kinase activity, resulting in the disassembly of Crk-mediated signaling complexes and abrogation of Crk-mediated signaling. On the other hand, Y251 in the SH3 domain interacts with the SH2 domain of Abl and releases the latch and clamp structure of Abl, leading to the activation of Abl. 
significantly weakens the binding of Abi1 to Abl [90]. Abi2 binds Abl at two sites: one is through the $\mathrm{SH} 3$ domain of $\mathrm{Abl}$ and the $\mathrm{P}-\mathrm{x}-\mathrm{x}-\mathrm{P}$ motif of Abi2, and the other is through the $\mathrm{P}-\mathrm{x}-\mathrm{x}-\mathrm{P}$ motif of $\mathrm{Abl}$ and the Abi2 $\mathrm{SH} 3$ domain [62] (Figure 4(a)). Y324 of Abi2 is predicted as a site of phosphorylation by Abl based on a conserved flanking amino acid sequence (E-Y -S-D-P) [96] and is presumed to play a role in the regulation of Abl kinase activity [62]. However, since the Y213 and Y398 residues are also conserved in Abi2, pY213 and/or pY398 could play a role for Abi2 as in the case of Abil.

The modulation of Abl kinase by Crk occurs in discrete steps [84, 97] (Figure 4(b)). The initial and an essential event is the interaction between the $\mathrm{Crk} \mathrm{SH} 3(\mathrm{~N})$ domain and three of the four PR motifs of $\mathrm{Abl}$, inducing transactivation of c-Abl to phosphorylate CrkII at Y221 in the spacer region $[98,99]$. This phosphorylation induces an intramolecular SH2-pTyr clamp and suppression of the c-Abl kinase activity as well, resulting in the disassembly of Crk-mediated signaling complexes and abrogates downstream signaling [100]. In contrast, v-Crk lacks Y221 and hence is presumed to take an open structure constitutively [97]. In addition to Y221, a recent study identified Y251 in the RT loop of $\mathrm{SH} 3(\mathrm{C})$ as a second site of phosphorylation by Abl [101]. Y251, when phosphorylated, binds to the Abl SH2 domain to transactivate $\mathrm{Abl}$, demonstrating a positive regulatory mechanism by CrkII. In this regard, functional significance as well as similarity between Y251 in the CrkII SH3(C) and Y398 in the Abil SH3 may be noted, although the target domain Abl seems to be different. A form of CrkII phosphorylated at Y251 has been observed in CML cell lines [101]. Tyrosine phosphorylation of Crk thus can both positively and negatively regulate Abl kinase activity and its signaling cascades (Figure 4(b)). The SH2 and SH3 (N) domains may be required for bridging other cellular proteins as substrates by $\mathrm{Abl}$.

The interaction of $\mathrm{Abi}$ and $\mathrm{Crk}$ with $\mathrm{Abl}$ is also regulated by the phosphorylation of Abl by other protein kinases. For example, the serine/threonine kinase Pak2 phosphorylates c-Abl at $\mathrm{S} 637$ and $\mathrm{S} 638$ which reside next to the $\mathrm{P}-\mathrm{x}-\mathrm{x}-\mathrm{P}$ motif [102]. Phosphorylation at these sites weakens the binding of Abil, while enhancing the binding of Crk, resulting in an increase in Abl kinase activity. Taken together, Abil, Abi2, and Crk, as adaptor proteins, appear to regulate Abl in distinctive ways (Figure 4).

\section{Signaling Cascades in Abl-Mediated F-Actin Dynamics in Normal and CML Cells and Involvement of Abi and Crk}

5.1. Abl in Actin Dynamics. Abl transduces extracellular signals to cytoskeleton actin assembly/disassembly through its kinase activity. The actin-related protein-2/3 (Arp2/3) complex is a central player in the regulation of both the initiation of actin polymerization and the organization of the resulting filaments [103]. Members of the Wiscott-Aldrich syndrome protein (WASp) family have been identified as a nucleationpromoting factor (NPF) for the Arp2/3 complex; WASp, N
(neural)-WASp, and three WAVE (WASp-family verprolinhomologous protein) isoforms, WAVE 1, 2, and 3, are included in this family [103-105]. They form the nucleation complex of Rho GTPase-mediated actin polymerization by binding to the VCA domain of the WASp proteins at the Cterminus. Functional interaction between Abl and the WASP family has been observed. Namely, WAVE1 translocates to the cell membrane upon PDGF stimulation and is found in a complex containing $\mathrm{Abl}$ and other signaling proteins, inducing plasma membrane ruffling [106]. WAVE2 mediates actin reorganization by relaying signals from Racl to the Arp2/3 complex, resulting in a lamellipodial protrusion. Abldependent phosphorylation of WAVE2 is necessary for this process [107]. On the other hand, phosphorylation of NWASp at Y256 by Abl is required for shigella-promoted actin comet tail elongation [72]. This observation indicates that $\mathrm{Abl}$ could regulate N-WASP activity independent of the activation of the Rho GTPase family.

Mena (mammalian-enabled)/VASP (vasodilator-stimulated phosphoprotein) proteins interact with barbed ends of actin-filament and permit its elongation by preventing the capping of the barbed end: the anticapping hypothesis [108]. Indeed, Mena/VASP proteins colocalize to the tips of filopodia and lamellipodia and also at focal adhesion sites $[109,110]$. Functional interaction between Ena and Abl was first identified by genetic experiments in flies in which Ena functions as a suppressor of lethality associated with zygotic Abl mutations [111]. Indeed, dAbl can phosphorylate Ena at several tyrosine residues, reducing its ability to bind to SH3-domain-containing proteins [112]. In the mammalian system, Abl can target a single tyrosine residue in Mena [75], but the significance of this event is unclear. However, VASP coimmunoprecipitates with $\mathrm{Abl}$ in an adhesiondependent manner, suggesting the VASP protein complex functions cooperatively with $\mathrm{Abl}$ in F-actin reorganization [113].

Cells achieve cell-cell adhesion through cadherin receptors which are linked to the actin cytoskeleton through the catenin complex and are regulated by the Rho GTPase family [114]. E-cadherin interacts with the Arp2/3 complex to promote local actin assembly and lamellipodial protrusion during the formation of early cell-cell adhesion contacts [115]. Abl plays important roles in this intercellular signaling as well. Namely, cell-cell adhesion enhances Abl kinase activity through an as-yet-unknown mechanism, leading to increased CrkII phosphorylation by $\mathrm{Abl}$, and subsequent Rac activation through ELMO [116-118]. Conversely, when Abl kinase activity is lost, it leads to disruption of E-cadherinbased cell-cell contacts $[114,118]$.

5.2. Abi and Crk in Actin Dynamics. Adaptor proteins not only are important for the regulation of Abl as described above, but also regulate the downstream signaling machineries leading to acitn dynamics. Abi and Crk proteins bind Abl and also function as scaffold proteins that permit the assembly of respective multimolecular complexes (Figure 3(b)). This property confers essential but distinct roles to each Abi and Crk protein in Abl-mediated actin dynamics. 


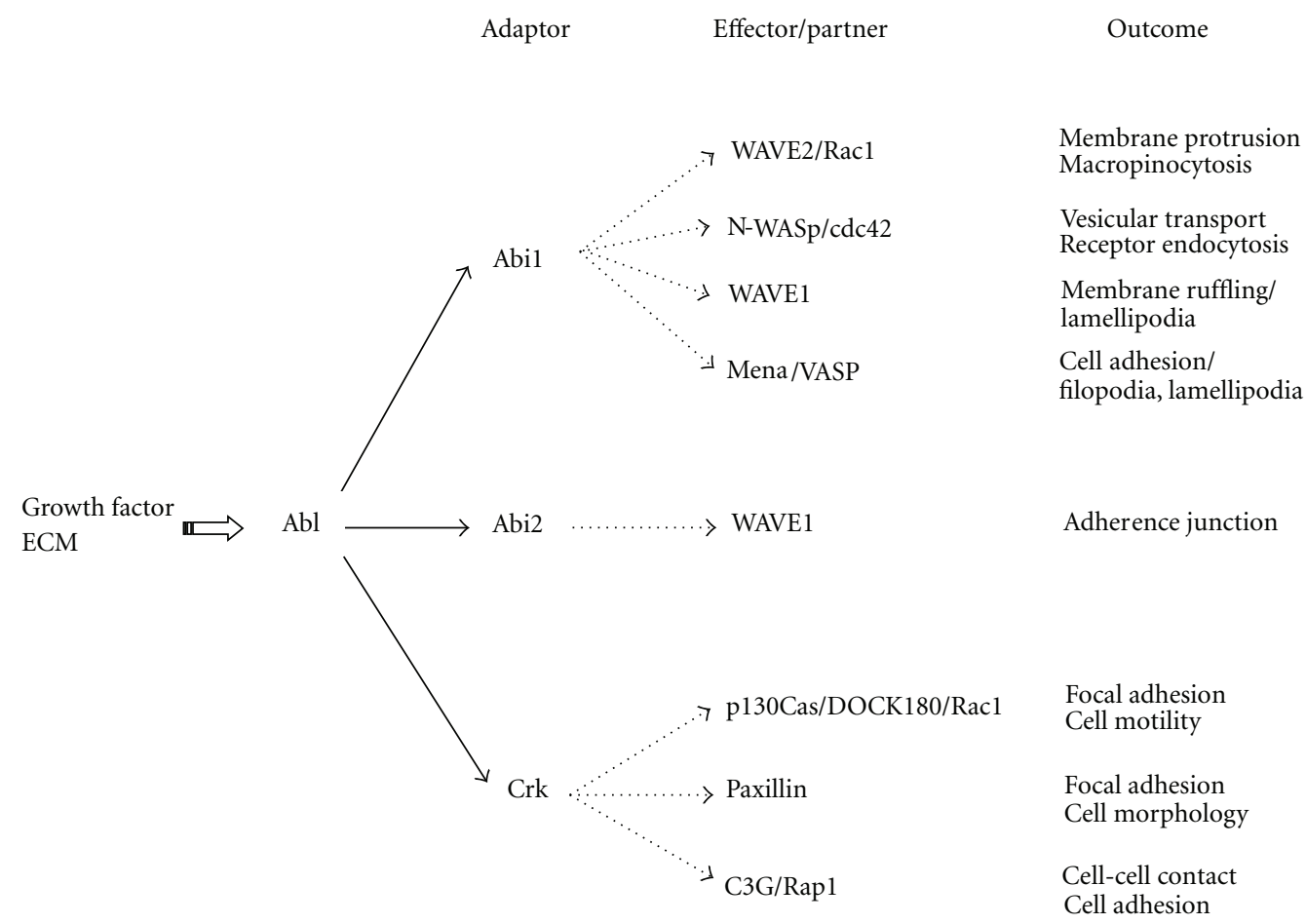

FIgURE 5: Differential roles of Abi and Crk in signaling pathways of Abl-mediated actin dynamics. Upstream and downstream signaling cascades of Abl-mediated actin dynamics are schematically illustrated (solid arrow). Downstream signaling pathways unique to each member of the Abi and Crk families are also shown together with the respective outcomes (broken arrow).

Indeed, focal adhesion proteins (e.g., paxillin, p130Cas, and Crk) and/or proteins found in filopodial structures (e.g., DOCK180, Abi, and PSTPIP) are included among the targets of Abl downstream of integrins [5]. Abil is essential for the stability and integrity of the WAVE complex [119121]. In the complex, WAVE1 binds to Abil through a region within WAVE1 WHD and promotes the localization to the tip of the lamellipodium [73]. On the other hand, Abil interacts directly with the WHD domain of WAVE2 and mediates the assembly of a WAVE2-Abi1-Nap1-PIR121 complex. Similar complexes are observed in Abi2 [118] and thought to act as an inhibitory complex for WAVE activity $[122,123]$. The Abi1/WAVE2 complex also plays important roles in F-actin dynamics stimulated by colony-stimulating factor-1 in dendritic cells [124] and by T-cell receptor at the T-cell and B-cell contact sites [125]. Regarding this, Abi1-promoted tyrosine phosphorylation at Y150 of WAVE2 by $\mathrm{Abl}$ was reported to be important in the regulation of membrane ruffling and dendritic morphogenesis [71]. While the Abil/WAVE complex plays a role in Rac-dependent membrane dynamics, the Abil/N-WASP complex, cooperating with cdc42, regulates actin-based vesicular transport, EGFR endocytosis, and EGFR and transferrin receptor cellsurface distribution. Thus, Abil is a dual regulator of WAVE and N-WASp activities in the respective processes [126].

Furthermore, Abil connects Abl and the substrate. Abil binds Mena and VASP through the polyproline region of Abi (Figure 3(b)) and promotes Abl-mediated phosphorylation at Y296 and Y39, respectively [75, 127]. Phosphorylation of VASP abrogates its affinity for Zyxin and subsequent accumulation at focal adhesion sites and modulates leukemic cell adhesion [127]. Furthermore, treatment with imatinib, a selective $\mathrm{Abl}$ inhibitor, increases the association of $\mathrm{Abl}$ at the lamellipodial cell edge, providing evidence that imatinib leads to the activated conformational change of Abl [128]. Thus, activated Abl presumably faces Mena/VASP and WAVE2 at the lamellipodial tip where Abil is localized and phosphorylates these substrates by an Abil-bridged mechanism [127]. While present in the WAVE complex, Abi3 does not promote Abl-mediated phosphorylation, suggesting differences among Abi family members in the regulation of Abl [129].

Bcr-Abl-positive leukemic cells exhibit abnormalities in cell motility, cell adhesion, and integrin function [130]. These characteristic properties are believed to play critical roles in the progression of CML. Abil plays an important role in these processes through direct interaction between its $\mathrm{SH} 3$ domain and the $\mathrm{C}$-terminal proline-rich sequences of Bcr-Abl [131]. Knockdown of the expression of Abi1 appeared to suppress Bcr-Abl-induced leukemogenesis in vivo and also inhibited Bcr-Abl-stimulated actin cytoskeleton remodeling, MT1-MMP clustering, and cell adhesion and migration in vitro $[132,133]$. Bcr-Abl subsequently induces tyrosine phosphorylation of Abil, accompanied by cellular translocation of the Abi1/WAVE2 complex to a site adjacent to the membrane, where an F-actin-enriched structure containing adhesion molecules such as $\beta 1$ integrin, paxillin, and vinculin is assembled. Phosphorylation of Abil was reported to enhance the phosphorylation of Mena by Abl, 
accompanying the enhanced adhesion of leukemic cells and Bcr-Abl transformed cells in vitro [90].

Crk, on the other hand, binds and activates Abl kinase as described above, inducing increased tyrosine phosphorylation of p130Cas [76]. The phosphorylated p130Cas then binds the Crk SH2 domain, while DOCK180 binds the Crk $\mathrm{SH} 3(\mathrm{~N})$ domain (Figure 3(b)), resulting in ternary complex of p130Cas-Crk-DOCK180, which is sufficient to activate Rac1 and localize to focal adhesion sites [134]. The formation of this complex is an important step in the Abl-mediated actin dynamics through Crk. Paxillin contains two $\mathrm{Y}-\mathrm{x}-\mathrm{x}-\mathrm{P}$ motifs and also binds the SH2 domain of Crk [135]. Paxillin is a substrate for several tyrosine kinases and functions as a scaffold to organize signal transduction proteins including $\alpha 4$ integrin into a large complex at focal adhesion sites [136]. These characteristic properties lead to an accumulation of Crk effectors bound via the Crk SH3 domain at sites of paxillin abundance. $\mathrm{C} 3 \mathrm{G}$ was the first $\mathrm{Crk} \mathrm{SH} 3(\mathrm{~N})$ domainbinding protein identified. $\mathrm{C} 3 \mathrm{G}$ is a guanine nucleotide releasing Rap1 whose targets have been implicated in cell proliferation, cytoskeletal reorganization during cell adhesion to ECM, and cell-to-cell contact $[114,118]$.

While the integrin-induced tyrosine phosphorylation of paxillin and p130Cas $[137,138]$ is associated with enhanced rates of fibroblast spreading and migration, tyrosine phosphorylation of Crk may negate these effects by disrupting the Abl:Crk: paxillin or Abl:Crk:p130Cas complex [139]. This raises the interesting possibility that Abl may both activate and inactivate cytoskeletal rearrangements at focal adhesion sites during cell spreading and migration and thereby attenuate cell migration by modulating cell adhesion and contractility [140]. Indeed, fibroblasts that are deficient in Abl migrate faster than wild-type controls, and reconstitution with Abl slows these cells [141, 142]. These results also highlight Crk as an important player in Abl-mediated actin dynamics and cell locomotion.

Finally, upstream signals and downstream signaling cascades of Abl-mediated actin dynamics are schematically summarized in Figure 5 in which signaling pathways unique to each adaptor protein are shown together with the respective outcomes.

\section{References}

[1] R. Plattner, L. Kadlec, K. A. Demali, A. Kazlauskas, and A. M. Pendergast, "c-Abl is activated by growth factors and Src family kinases and has a role in the cellular response to PDGF," Genes and Development, vol. 13, no. 18, pp. 24002411, 1999.

[2] A. Y. Ting, K. H. Kain, R. L. Klemke, and R. Y. Tsien, "Genetically encoded fluorescent reporters of protein tyrosine kinase activities in living cells," Proceedings of the National Academy of Sciences of the United States of America, vol. 98, no. 26, pp. 15003-15008, 2001.

[3] B. J. Mayer, "SH3 domains: complexity in moderation," Journal of Cell Science, vol. 114, no. 7, pp. 1253-1263, 2001.

[4] P. J. Woodring, T. Hunter, and J. Y. J. Wang, "Regulation of F-actin-dependent processes by the Abl family of tyrosine kinases," Journal of Cell Science, vol. 116, no. 13, pp. 26132626, 2003.
[5] W. D. Bradley and A. J. Koleske, "Regulation of cell migration and morphogenesis by Abl-family kinases: emerging mechanisms and physiological contexts," Journal of Cell Science, vol. 122, no. 19, pp. 3441-3454, 2009.

[6] J. Colicelli, "ABL tyrosine kinases: evolution of function, regulation, and specificity," Science Signaling, vol. 3, no. 139, article re6, 2010.

[7] P. J. Woodring, E. David Litwack, D. D. M. O’Leary, G. R. Lucero, J. Y. J. Wang, and T. Hunter, "Modulation of the Factin cytoskeleton by c-Abl tyrosine kinase in cell spreading and neurite extension," Journal of Cell Biology, vol. 156, no. 5, pp. 879-892, 2002.

[8] H. Pluk, K. Dorey, and G. Superti-Furga, "Autoinhibition of c-Abl," Cell, vol. 108, no. 2, pp. 247-259, 2002.

[9] B. Nagar, O. Hantschel, M. A. Young et al., "Structural basis for the autoinhibition of c-Abl tyrosine kinase," Cell, vol. 112, no. 6, pp. 859-871, 2003.

[10] S. Chen, L. P. O’Reilly, T. E. Smithgall, and J. R. Engen, "Tyrosine phosphorylation in the $\mathrm{SH} 3$ domain disrupts negative regulatory interactions within the c-Abl kinase core," Journal of Molecular Biology, vol. 383, no. 2, pp. 414423, 2008.

[11] S. Chen, T. P. Dumitrescu, T. E. Smithgall, and J. R. Engen, "Abl N-terminal cap stabilization of SH3 domain dynamics," Biochemistry, vol. 47, no. 21, pp. 5795-5803, 2008.

[12] P. Filippakopoulous, S. Muller, and S. Knapp, "SH2 domains: modulators of nonreceptor tyrosine kinase activity," Current Opinion in Structural Biology, vol. 19, no. 6, pp. 643-649, 2009.

[13] S. P. Goff, E. Gilboa, O. N. Witte, and D. Baltimore, "Structure of the Abelson murine leukemia virus genome and the homologous cellular gene: studies with cloned viral DNA," Cell, vol. 22, no. 3, pp. 777-785, 1980.

[14] E. P. Reddy, M. J. Smith, and A. Srinivasan, "Nucleotide sequence of Abelson murine leukemia virus genome: structural similarity of its transforming gene product to other onc gene products with tyrosine-specific kinase activity," Proceedings of the National Academy of Sciences of the United States of America, vol. 80, no. 12, pp. 3623-3627, 1983.

[15] J. Y. J. Wang, F. Ledley, S. Goff, R. Lee, Y. Groner, and D. Baltimore, "The mouse c-abl locus: molecular cloning and characterization,” Cell, vol. 36, no. 2, pp. 349-356, 1984.

[16] J. B. Konopka, S. M. Watanabe, J. W. Singer, S. J. Collins, and O. N. Witte, "Cell lines and clinical isolates derived from Ph1positive chronic myelogenous leukemia patients express c-abl proteins with a common structural alteration," Proceedings of the National Academy of Sciences of the United States of America, vol. 82, no. 6, pp. 1810-1814, 1985.

[17] Y. Ben-Neriah, G. Q. Daley, A. M. Mes-Masson, O. N. Witte, and D. Baltimore, "The chronic myelogenous leukemiaspecific P210 protein is the product of the bcr/abl hybrid gene," Science, vol. 233, no. 4760, pp. 212-214, 1986.

[18] G. D. Kruh, R. Perego, T. Miki, and S. A. Aaronson, "The complete coding sequence of arg defines the Abelson subfamily of cytoplasmic tyrosine kinases," Proceedings of the National Academy of Sciences of the United States of America, vol. 87, no. 15, pp. 5802-5806, 1990.

[19] H. Hoffman-Falk, P. Einat, B. Shilo, and F. Hoffmann, "Drosophila melanogaster DNA clones homologous to vertebrate oncogenes: evidence for a common ancestor to the src and abl cellular genes," Cell, vol. 32, no. 2, pp. 589-598, 1983.

[20] J. M. Goddard, J. J. Weiland, and M. R. Capecchi, "Isolation and characterization of Caenorhabditis elegans DNA sequences homologous to the v-abl oncogene," Proceedings 
of the National Academy of Sciences of the United States of America, vol. 83, no. 7, pp. 2172-2176, 1986.

[21] P. L. Schwartzberg, A. M. Stall, J. D. Hardin et al., "Mice homozygous for the ablm1 mutation show poor viability and depletion of selected B and T cell populations," Cell, vol. 65, no. 7, pp. 1165-1175, 1991.

[22] V. L. J. Tybulewicz, C. E. Crawford, P. K. Jackson, R. T. Bronson, and R. C. Mulligan, "Neonatal lethality and lymphopenia in mice with a homozygous disruption of the c-abl proto-oncogene," Cell, vol. 65, no. 7, pp. 1153-1163, 1991.

[23] H. Brightbill and M. S. Schlissel, "The effects of c-Abl mutation on developing B cell differentiation and survival," International Immunology, vol. 21, no. 5, pp. 575-585, 2009.

[24] R. A. Liberatore and S. P. Goff, "c-Abl-deficient mice exhibit reduced numbers of peritoneal B-1 cells and defects in BCRinduced B cell activation," International Immunology, vol. 21, no. 4, pp. 403-414, 2009.

[25] I. Silberman, R. V. Sionov, V. Zuckerman et al., "T cell survival and function requires the c-Abl tyrosine kinase," Cell Cycle, vol. 7, no. 24, pp. 3847-3857, 2008.

[26] B. Li, S. Boast, K. de los Santos et al., "Mice deficient in Abl are osteoporotic and have defects in osteoblast maturation," Nature Genetics, vol. 24, no. 3, pp. 304-308, 2000.

[27] A. J. Koleske, A. M. Gifford, M. L. Scott et al., "Essential roles for the Abl and Arg tyrosine kinases in neurulation," Neuron, vol. 21, no. 6, pp. 1259-1272, 1998.

[28] D. Srinivasan and R. Plattner, "Activation of Abl tyrosine kinases promotes invasion of aggressive breast cancer cells," Cancer Research, vol. 66, no. 11, pp. 5648-5655, 2006.

[29] T. P. Newsome, I. Weisswange, F. Frischknecht, and M. Way, "Abl collaborates with Src family kinases to stimulate actinbased motility of vaccinia virus," Cellular Microbiology, vol. 8, no. 2, pp. 233-241, 2006.

[30] S. Backert, S. M. Feller, and S. Wessler, "Emerging roles of Abl family tyrosine kinases in microbial pathogenesis," Trends in Biochemical Sciences, vol. 33, no. 2, pp. 80-90, 2008.

[31] J. R. Mcwhirter and J. Y. J. Wang, "An actin-binding function contributes to transformation by the Bcr-Abl oncoprotein of Philadelphia chromosome-positive human leukemias," The EMBO Journal, vol. 12, no. 4, pp. 1533-1546, 1993.

[32] R. A. van Etten, P. K. Jackson, D. Baltimore, M. C. Sanders, P. T. Matsudaira, and P. A. Janmey, "The $\mathrm{COOH}$ terminus of the $\mathrm{c}-a b l$ tyrosine kinase contains distinct F- and G-actin binding domains with bundling activity," Journal of Cell Biology, vol. 124, no. 3, pp. 325-340, 1994.

[33] Y. Wang, A. L. Miller, M. S. Mooseker, and A. J. Koleske, "The Abl-related gene (Arg) nonreceptor tyrosine kinase uses two F-actin-binding domains to bundle F-actin," Proceedings of the National Academy of Sciences of the United States of America, vol. 98, no. 26, pp. 14865-14870, 2001.

[34] E. T. Kipreos and J. Y. J. Wang, "Cell cycle-regulated binding of c-Abl tyrosine kinase to DNA," Science, vol. 256, no. 5055, pp. 382-385, 1992.

[35] M. H. David-Cordonnier, M. Hamdane, C. Bailly, and J. C. D'Halluin, "Determination of the human c-Abl consensus DNA binding site," The FEBS Letters, vol. 424, no. 3, pp. 177$182,1998$.

[36] B. R. Henderson and A. Eleftheriou, "A comparison of the activity, sequence specificity, and CRM1-dependence of different nuclear export signals," Experimental Cell Research, vol. 256, no. 1, pp. 213-224, 2000.

[37] S. Taagepera, D. Mcdonald, J. E. Loeb et al., "Nuclearcytoplasmic shuttling of c-Abl tyrosine kinase," Proceedings of the National Academy of Sciences of the United States of America, vol. 95, no. 13, pp. 7457-7462, 1998.

[38] Y. Shaul, "c-Abl: activation and nuclear targets," Cell Death and Differentiation, vol. 7, no. 1, pp. 10-16, 2000.

[39] J. Y. J. Wang, "Regulation of cell death by the Abl tyrosine kinase," Oncogene, vol. 19, no. 49, pp. 5643-5650, 2000.

[40] J. M. Lewis, R. Baskaran, S. Taagepera, M. A. Schwartz, and J. Y. J. Wang, "Integrin regulation of c-Abl tyrosine kinase activity and cytoplasmic-nuclear transport," Proceedings of the National Academy of Sciences of the United States of America, vol. 93, no. 26, pp. 15174-15179, 1996.

[41] R. A. van Etten, P. Jackson, and D. Baltimore, "The mouse type IV c-abl gene product is a nuclear protein, and activation of transforming ability is associated with cytoplasmic localization," Cell, vol. 58, no. 4, pp. 669-678, 1989.

[42] A. M. Mes-Masson, J. McLaughlin, G. Q. Daley, M. Paskind, and O. N. Witte, "Overlapping cDNA clones define the complete coding region for the $\mathrm{P} 210 \mathrm{c}-\mathrm{abl}$ gene product associated with chronic myelogenous leukemia cells containing the Philadelphia chromosome," Proceedings of the National Academy of Sciences of the United States of America, vol. 83, pp. 9768-9772, 1986.

[43] T. Takeya and H. Hanafusa, "Structure and sequence of the cellular gene homologous to the RSV src gene and the mechanism for generating the transforming virus," Cell, vol. 32, no. 3, pp. 881-890, 1983.

[44] K. M. Smith, R. Yacobi, and R. A. van Etten, "Autoinhibition of Bcr-Abl through its SH3 domain," Molecular Cell, vol. 12, no. 1, pp. 27-37, 2003.

[45] O. Hantschel, B. Nagar, S. Guettler et al., "A myristoyl/phosphotyrosine switch regulates c-Abl," Cell, vol. 112, no. 6, pp. 845-857, 2003.

[46] B. Nagar, O. Hantschel, M. Seeliger et al., "Organization of the $\mathrm{SH} 3-\mathrm{SH} 2$ unit in active and inactive forms of the c-Abl tyrosine kinase," Molecular Cell, vol. 21, no. 6, pp. 787-798, 2006.

[47] B. B. Brasher and R. A. van Etten, "c-Abl has high intrinsic tyrosine kinase activity that is stimulated by mutation of the Src homology 3 domain and by autophosphorylation at two distinct regulatory tyrosines," The Journal of Biological Chemistry, vol. 275, no. 45, pp. 35631-35637, 2000.

[48] O. Furstoss, K. Dorey, V. Simon, D. Barilà, G. Superti-Furga, and S. Roche, "c-Abl is an effector of Src for growth factorinduced c-myc expression and DNA synthesis," The EMBO Journal, vol. 21, no. 4, pp. 514-524, 2002.

[49] K. Q. Tanis, D. Veach, H. S. Duewel, W. G. Bornmann, and A. J. Koleske, "Two distinct phosphorylation pathways have additive effects on Abl family kinase activation," Molecular and Cellular Biology, vol. 23, no. 11, pp. 3884-3896, 2003.

[50] P. Derkinderen, T. M. E. Scales, D. P. Hanger et al., "Tyrosine 394 is phosphorylated in Alzheimer's paired helical filament tau and in fetal tau with $\mathrm{c}-\mathrm{Abl}$ as the candidate tyrosine kinase," Journal of Neuroscience, vol. 25, no. 28, pp. 65846593, 2005.

[51] B. J. Mayer and D. Baltimore, "Mutagenic analysis of the roles of $\mathrm{SH} 2$ and $\mathrm{SH} 3$ domains in regulation of the Abl tyrosine kinase," Molecular and Cellular Biology, vol. 14, no. 5, pp. 2883-2894, 1994.

[52] D. Barila and G. Superti-Furga, "An intramolecular SH3domain interaction regulates c-Abl activity," Nature Genetics, vol. 18, no. 3, pp. 280-282, 1998.

[53] M. A. Meyn III, M. B. Wilson, F. A. Abdi et al., "Src family kinases phosphorylate the $\mathrm{Bcr}-\mathrm{Abl} \mathrm{SH3}-\mathrm{SH} 2$ region 
and modulate Bcr-Abl transforming activity," The Journal of Biological Chemistry, vol. 281, no. 41, pp. 30907-30916, 2006.

[54] P. J. Woodring, T. Hunter, and J. Y. J. Wang, "Inhibition of c-Abl Tyrosine Kinase Activity by Filamentous Actin," The Journal of Biological Chemistry, vol. 276, no. 29, pp. 2710427110, 2001.

[55] B. J. Mayer, M. Hamaguchi, and H. Hanafusa, "A novel viral oncogene with structural similarity to phospholipase C," Nature, vol. 332, no. 6161, pp. 272-275, 1988.

[56] C. T. Reichman, B. J. Mayer, S. Keshav, and H. Hanafusa, "The product of the cellular crk gene consists primarily of SH2 and SH3 regions," Cell Growth \& Differentiation, vol. 3, no. 7, pp. 451-460, 1992.

[57] M. Matsuda, S. Tanaka, S. Nagata, A. Kojima, T. Kurata, and M. Shibuya, "Two species of human CRK cDNA encode proteins with distinct biological activities," Molecular and Cellular Biology, vol. 12, no. 8, pp. 3482-3489, 1992.

[58] J. Ten Hoeve, C. Morris, N. Heisterkamp, and J. Groffen, "Isolation and chromosomal localization of CRKL, a human crk-like gene," Oncogene, vol. 8, no. 9, pp. 2469-2474, 1993.

[59] T. Shishido, M. Sato, M. Maruoka, and K. Tani, "Abelson inteactor (Abi) family proteins and cancer," Adaptor Proteins and Cancer (Ed. M.M. Georgescu), pp. 103-120, 2008.

[60] V. L. Goss, K. A. Lee, A. Moritz et al., "A common phosphotyrosine signature for the Bcr-Abl kinase," Blood, vol. 107, no. 12, pp. 4888-4897, 2006.

[61] Z. Biesova, C. Piccoli, and W. T. Wong, "Isolation and characterization of e3B1, an eps 8 binding protein that regulates cell growth,” Oncogene, vol. 14, no. 2, pp. 233-241, 1997.

[62] Z. Dai and A. M. Pendergast, "Abi-2, a novel SH3-containing protein interacts with the c-Abl tyrosine kinase and modulates c-Abl transforming activity," Genes and Development, vol. 9, no. 21, pp. 2569-2582, 1995.

[63] B. Wang, E. A. Golemis, and G. D. Kruh, "ArgBP2, a multiple Src homology 3 domain-containing, Arg/Abl-interacting protein, is phosphorylated in v-Abl-transformed cells and localized in stress fibers and cardiocyte Z-disks," The Journal of Biological Chemistry, vol. 272, no. 28, pp. 17542-17550, 1997.

[64] V. Ribon, R. Herrera, B. K. Kay, and A. R. Saltiel, "A role for CAP, a novel, multifunctional Src homology 3 domaincontaining protein in formation of actin stress fibers and focal adhesions," The Journal of Biological Chemistry, vol. 273, no. 7, pp. 4073-4080, 1998.

[65] K. Mandai, H. Nakanishi, A. Satoh et al., "Ponsin/SH3P12: an 1-afadin- and vinculin-binding protein localized at cell-cell and cell-matrix adherens junctions," Journal of Cell Biology, vol. 144, no. 5, pp. 1001-1017, 1999.

[66] N. Kioka, S. Sakata, T. Kawauchi et al., "Vinexin: a novel vinculin-binding protein with multiple $\mathrm{SH} 3$ domains enhances actin cytoskeletal organization," Journal of Cell Biology, vol. 144, no. 1, pp. 58-69, 1999.

[67] J. M. Smith, S. Katz, and B. J. Mayer, "Activation of the Abl tyrosine kinase in vivo by Src homology 3 domains from the Src homology 2/Src homology 3 adaptor Nck," The Journal of Biological Chemistry, vol. 274, no. 39, pp. 27956-27962, 1999.

[68] R. Salgia, M. Sattle, E. Pisick, J. L. Li, and J. D. Griffin, "p210BCR/ABL induces formation of complexes containing focal adhesion proteins and the protooncogene product p120c-Cbl," Experimental Hematology, vol. 24, no. 2, pp. 310313, 1996.

[69] S. M. Feller, "CrK family adaptors-signalling complex formation and biological roles," Oncogene, vol. 20, no. 44, pp. 63486371, 2001.
[70] R. B. Birge, C. Kalodimos, F. Inagaki, and S. Tanaka, "Crk and CrkL adaptor proteins: networks for physiological and pathological signaling," Cell Communication and Signaling, vol. 7, article 13, 2009.

[71] Y. Leng, J. Zhang, K. Badour et al., "Abelson-interactor1 promotes WAVE2 membrane translocation and Abelsonmediated tyrosine phosphory lation required for WAVE2 activation," Proceedings of the National Academy of Sciences of the United States of America, vol. 102, no. 4, pp. 1098-1103, 2005.

[72] E. A. Burton, T. N. Oliver, and A. M. Pendergast, "Abl kinases regulate actin comet tail elongation via an N-WASPdependent pathway," Molecular and Cellular Biology, vol. 25, no. 20, pp. 8834-8843, 2005.

[73] A. Echarri, M. J. Lai, M. R. Robinson, and A. M. Pendergast, "Abl interactor 1 (Abi-1) wave-binding and SNARE domains regulate its nucleocytoplasmic shuttling, lamellipodium localization, and Wave-1 levels," Molecular and Cellular Biology, vol. 24, no. 11, pp. 4979-4993, 2004.

[74] T. Y. Lin, C. H. Huang, W. G. Chou, and J. L. Juang, "Abi enhances Abl-mediated Cdc2 phosphorylation and inactivation," Journal of Biomedical Science, vol. 11, no. 6, pp. 902-910, 2004.

[75] K. Tani, S. Sato, T. Sukezane et al., "Abl interactor 1 promotes tyrosine 296 phosphorylation of mammalian enabled (Mena) by c-Abl kinase," The Journal of Biological Chemistry, vol. 278, no. 24, pp. 21685-21692, 2003.

[76] Y. Kobashigawa, M. Sakai, M. Naito et al., "Structural basis for the transforming activity of human cancer-related signaling adaptor protein CRK," Nature Structural and Molecular Biology, vol. 14, no. 6, pp. 503-510, 2007.

[77] Y. Shi, K. Alin, and S. P. Goff, "Abl-interactor-1, a novel SH3 protein binding to the carboxy-terminal portion of the Abl protein, suppresses v-abl transforming activity," Genes and Development, vol. 9, no. 21, pp. 2583-2597, 1995.

[78] K. Miyazaki, S. Matsuda, Y. Ichigotani et al., "Isolation and characterization of a novel human gene (NESH) which encodes a putative signaing molecule similar to e3B1 proteins," Biochimica et Biophysica Acta, vol. 1493, no. 1-2, pp. 237-241, 2000.

[79] S. Panigrahi, J. Stetefeld, J. R. Jangamreddy, S. Mandal, S. K. Mandal, and M. Los, "Modeling of molecular interaction between apoptin, Bcr-Abl and CrkL-an alternative approach to conventional rational drug design," PloS One, vol. 7, no. 1, Article ID e28395, 2012.

[80] P. M. Dubielecka, K. I. Ladwein, X. Xiong et al., "Essential role for Abil in embryonic survival and WAVE2 complex integrity," Proceedings of the National Academy of Sciences of the United States of America, vol. 108, no. 17, pp. 7022-7027, 2011.

[81] C. Ring, M. H. Ginsberg, J. Haling, and A. M. Pendergast, "Abl-interactor-1 (Abi1) has a role in cardiovascular and placental development and is a binding partner of the $\alpha 4$ integrin," Proceedings of the National Academy of Sciences of the United States of America, vol. 108, no. 1, pp. 149-154, 2011.

[82] M. Grove, G. Demyanenko, A. Echarri et al., "Abi2-deficient mice exhibit defective cell migration, aberrant dendritic spine morphogenesis, and deficits in learning and memory," Molecular and Cellular Biology, vol. 24, no. 24, pp. 1090510922, 2004.

[83] T. J. Park, K. Boyd, and T. Curran, "Cardiovascular and craniofacial defects in Crk-null mice," Molecular and Cellular Biology, vol. 26, no. 16, pp. 6272-6282, 2006. 
[84] T. Shishido and J. Suzuki, "Regulation of Abl kinases by adaptor proteins," Gene Therapy and Molecular Biology, vol. 19, pp. 339-342, 2005.

[85] P. D. Fan, F. Cong, and S. P. Goff, "Homo- and heterooligomerization of the $\mathrm{c}$-Abl kinase and abelson-interactor1," Cancer Research, vol. 63, no. 4, pp. 873-877, 2003.

[86] A. R. Salomon, S. B. Ficarro, L. M. Brill et al., "Profiling of tyrosine phosphorylation pathways in human cells using mass spectrometry," Proceedings of the National Academy of Sciences of the United States of America, vol. 100, no. 2, pp. 443-448, 2003.

[87] M. Innocenti, E. Frittoli, I. Ponzanelli et al., "Phosphoinositide 3-kinase activates Rac by entering in a complex with Eps8, Abil, and Sos-1," Journal of Cell Biology, vol. 160, no. 1, pp. 17-23, 2003.

[88] C. Proepper, S. Johannsen, S. Liebau et al., "Abelson interacting protein 1 (Abi-1) is essential for dendrite morphogenesis and synapse formation," The EMBO Journal, vol. 26, no. 5, pp. 1397-1409, 2007.

[89] X. Xiong, P. Cui, S. Hossain et al., "Allosteric inhibition of the nonMyristoylated c-Abl tyrosine kinase by phosphopeptides derived from Abi1/Hssh3bp1," Biochimica et Biophysica Acta, vol. 1783 , no. 5 , pp. 737-747, 2008.

[90] M. Sato, M. Maruoka, N. Yokota et al., "Identification and functional analysis of a new phosphorylation site (Y398) in the SH3 domain of Abi-1," The FEBS Letters, vol. 585, no. 6, pp. 834-840, 2011.

[91] T. P. Cujec, P. F. Medeiros, P. Hammond, C. Rise, and B. L. Kreider, "Selection of v-abl tyrosine kinase substrate sequences from randomized peptide and cellular proteomic libraries using mRNA display," Chemistry and Biology, vol. 9, no. 2, pp. 253-264, 2002.

[92] GenBank, CAX15877.1.

[93] P. M. Dubielecka, K. Machida, X. Xiong et al., "Abil/ Hssh3bp1 pY213 links Abl kinase signaling to p85 regulatory subunit of PI-3 kinase in regulation of macropinocytosis in LNCaP cells," The FEBS Letters, vol. 584, no. 15, pp. 32793286, 2010.

[94] P. Filippakopoulos, M. Kofler, O. Hantschel et al., "Structural coupling of SH2-kinase domains links Fes and Abl substrate recognition and kinase activation," Cell, vol. 134, no. 5, pp. 793-803, 2008.

[95] S. M. Larson and A. R. Davidson, "The identification of conserved interactions within the $\mathrm{SH} 3$ domain by alignment of sequences and structures," Protein Science, vol. 9, no. 11, pp. 2170-2180, 2000.

[96] Z. Songyang, K. L. Carraway III, M. J. Eck et al., "Catalytic specificity of protein-tyrosine kinases is critical for selective signaling," Nature, vol. 373, pp. 536-539, 1995.

[97] T. Shishido, T. Akagi, A. Chalmers et al., "Crk family adaptor proteins trans-activate c-Abl kinase," Genes to Cells, vol. 6, no. 5, pp. 431-440, 2001.

[98] R. Ren, Z. S. Ye, and D. Baltimore, "Ab1 protein-tyrosine kinase selects the Crk adapter as a substrate using $\mathrm{SH} 3$ binding sites," Genes and Development, vol. 8, no. 7, pp. 783795, 1994.

[99] S. M. Feller, B. Knudsen, and H. Hanafusa, "c-Abl kinase regulates the protein binding activity of c-Crk," The EMBO Journal, vol. 13, no. 10, pp. 2341-2351, 1994.

[100] M. K. Rosen, T. Yamazaki, G. D. Gish, C. M. Kay, T. Pawson, and L. E. Kay, "Direct demonstration of an intramolecular SH2-phosphotyrosine interaction in the Crk protein," Nature, vol. 374, no. 6521, pp. 477-479, 1995.
[101] G. Sriram, C. Reichman, A. Tunceroglu et al., "Phosphorylation of Crk on tyrosine 251 in the RT loop of the SH3C domain promotes Abl kinase transactivation," Oncogene, vol. 30, pp. 4644-4655, 2011.

[102] J. H. Jung, A. M. Pendergast, P. A. Zipfel, and J. A. Traugh, "Phosphorylation of c-Abl by protein kinase Pak2 regulates differential binding of ABI2 and CRK," Biochemistry, vol. 47, no. 3, pp. 1094-1104, 2008.

[103] E. D. Goley and M. D. Welch, "The ARP2/3 complex: an actin nucleator comes of age," Nature Reviews Molecular Cell Biology, vol. 7, no. 10, pp. 713-726, 2006.

[104] T. Takenawa and S. Suetsugu, "The WASP-WAVE protein network: connecting the membrane to the cytoskeleton," Nature Reviews Molecular Cell Biology, vol. 8, no. 1, pp. 3748, 2007.

[105] A. Y. Pollitt and R. H. Insall, "WASP and SCAR/WAVE proteins: the drivers of actin assembly," Journal of Cell Science, vol. 122, no. 15, pp. 2575-2578, 2009.

[106] R. S. Westphal, S. H. Soderling, N. M. Alto, L. K. Langeberg, and J. D. Scott, "Scar/WAVE-1, a Wiskott-Aldrich syndrome protein, assembles an actin-associated multi-kinase scaffold," The EMBO Journal, vol. 19, no. 17, pp. 4589-4600, 2000.

[107] J. R. Stuart, F. H. Gonzalez, H. Kawai, and Z. M. Yuan, "c-Abl interacts with the WAVE2 signaling complex to induce membrane ruffling and cell spreading," The Journal of Biological Chemistry, vol. 281, no. 42, pp. 31290-31297, 2006.

[108] J. E. Bear and F. B. Gertler, "Ena/VASP: towards resolving a pointed controversy at the barbed end," Journal of Cell Science, vol. 122, no. 12, pp. 1947-1953, 2009.

[109] K. Rottner, B. Behrendt, J. V. Small, and J. Wehland, "VASP dynamics during lamellipodia protrusion," Nature Cell Biology, vol. 1, no. 5, pp. 321-322, 1999.

[110] F. B. Gertler, K. Niebuhr, M. Reinhard, J. Wehland, and P. Soriano, "Mena, a relative of VASP and Drosophila enabled, is implicated in the control of microfilament dynamics," Cell, vol. 87, no. 2, pp. 227-239, 1996.

[111] F. B. Gertler, J. S. Doctor, and F. M. Hoffmann, "Genetic suppression of mutations in the Drosophila abl protooncogene homolog," Science, vol. 248, no. 4957, pp. 857-860, 1990.

[112] A. R. Comer, S. M. Ahern-Djamali, J. L. Juang, P. D. Jackso, and F. M. Hoffman, "Phosphorylation of enabled by the Drosophila Abelson tyrosine kinase regulates the in vivo function and protein-protein interactions of enabled," Molecular and Cellular Biology, vol. 18, no. 1, pp. 152-160, 1998.

[113] A. K. Howe, B. P. Hogan, and R. L. Juliano, "Regulation of vasodilator-stimulated phosphoprotein phosphorylation and interaction with Abl by protein kinase A and cell adhesion," The Journal of Biological Chemistry, vol. 277, no. 41, pp. 38121-38126, 2002.

[114] N. L. Zandy, M. Playford, and A. M. Pendergast, "Abl tyrosine kinases regulate cell-cell adhesion through Rho GTPases," Proceedings of the National Academy of Sciences of the United States of America, vol. 104, no. 45, pp. 17686-17691, 2007.

[115] E. M. Kovacs, M. Goodwin, R. G. Ali, A. D. Paterson, and A. S. Yap, "Cadherin-directed actin assembly: E-cadherin physically associates with the Arp2/3 complex to direct actin assembly in nascent adhesive contacts," Current Biology, vol. 12, no. 5, pp. 379-382, 2002.

[116] E. Brugnera, L. Haney, C. Grimsley et al., "Unconventional Rac-GEF activity is mediated through the Dock180-ELMO complex," Nature Cell Biology, vol. 4, no. 8, pp. 574-582, 2002. 
[117] M. Lu, J. M. Kinchen, K. L. Rossman et al., "PH domain of ELMO functions in trans to regulate Rac activation via Dock180," Nature Structural and Molecular Biology, vol. 11, no. 8, pp. 756-762, 2004.

[118] N. L. Zandy and A. M. Pendergast, "Abl tyrosine kinases modulate cadherin-dependent adhesion upstream and downstream of Rho family GTPases," Cell Cycle, vol. 7, no. 4, pp. 444-448, 2008.

[119] S. Eden, R. Rohalgi, A. V. Podelelejnikov, M. Mann, and M. W. Kirschner, "Mechanisms of regulation of WAVE1-induced actin nucleation by Rac1 and Nck," Nature, vol. 418, no. 6899, pp. 790-793, 2002.

[120] M. Innocenti, A. Zucconi, A. Disanza et al., "Abil is essential for the formation and activation of a WAVE2 signalling complex," Nature Cell Biology, vol. 6, no. 4, pp. 319-327, 2004.

[121] A. Gautreau, H. Y. H. Ho, J. Li, H. Steen, S. P. Gygi, and M. W. Kirschner, "Purification and architecture of the ubiquitous Wave complex," Proceedings of the National Academy of Sciences of the United States of America, vol. 101, no. 13, pp. 4379-4383, 2004.

[122] E. Derivery and A. Gautreau, "Generation of branched actin networks: assembly and regulation of the N-WASP and WAVE molecular machines," BioEssays, vol. 32, no. 2, pp. 119-131, 2010.

[123] Z. Chen, D. Borek, S. B. Padrick et al., "Structure and control of the actin regulatory WAVE complex," Nature, vol. 468, no. 7323, pp. 533-538, 2010.

[124] W. A. Kheir, J. C. Gevrey, H. Yamaguchi, B. Isaac, and D. Cox, "A WAVE2-Abil complex mediates CSF-1-induced F-actinrich membrane protrusions and migration in macrophages," Journal of Cell Science, vol. 118, no. 22, pp. 5369-5379, 2005.

[125] P. A. Zipfel, S. C. Bunnell, D. S. Witherow et al., "Role for the Abi/Wave protein complex in $\mathrm{T}$ cell receptor-mediated proliferation and cytoskeletal remodeling," Current Biology, vol. 16, no. 1, pp. 35-46, 2006.

[126] M. Innocenti, S. Gerboth, K. Rottner et al., "Abil regulates the activity of N-WASP and WAVE in distinct actin-based processes," Nature Cell Biology, vol. 7, pp. 969-976, 2005.

[127] M. Maruoka, M. Sato, Y. Yuan et al., "Abi-1-bridged tyrosine phosphorylation of VASP by Abelson kinase impairs association of VASP to focal adhesions and regulates leukemic cell adhesion," Biochemical Journal, vol. 441, no. 3, pp. 889-999, 2012.

[128] A. Fujita, T. Shishido, Y. Yuan, E. Inamoto, S. Narumiya, and N. Watanabe, "Imatinib mesylate (STI571)-induced cell edge translocation of kinase-active and kinase-defective abelson kinase: requirements of myristoylation and src homology 3 domain," Molecular Pharmacology, vol. 75, no. 1, pp. 75-84, 2009.

[129] N. Hirao, S. Sato, T. Gotoh et al., "NESH (Abi-3) is present in the Abi/WAVE complex but does not promote c-Ablmediated phosphorylation," The FEBS Letters, vol. 580, no. 27, pp. 6464-6470, 2006.

[130] G. Bazzoni, N. Carlesso, J. D. Griffin, and M. E. Hmler, "Bcr/Abl expression stimulates integrin function in hematopoietic cell line," Journal of Clinical Investigation, vol. 98, no. 2, pp. 521-528, 1996.

[131] Y. Li, N. Clough, X. Sun et al., "Bcr-Abl induces abnormal cytoskeletal remodeling, beta 1 interin clustering and increase cell adhesion to fibronectin through the Abl interactor 1 pathway," Journal of Cell Science, vol. 120, pp. 14361446, 2007.
[132] W. Yu, X. Sun, N. Clough, E. Cobos, Y. Tao, and Z. Dai, "Abil gene silencing by short hairpin RNA impairs Bcr-Abl-induced cell adhesion and migration in vitro and leukemogenesis in vivo," Carcinogenesis, vol. 29, no. 9, pp. 1717-1724, 2008.

[133] X. Sun, Y. Li, W. Yu, B. Wang, Y. Tao, and Z. Dai, "MT1MMP as a downstream target of BCR-ABL/ABL interactor 1 signaling: polarized distribution and involvement in BCRABL-stimulated leukemic cell migration," Leukemia, vol. 22, no. 5, pp. 1053-1056, 2008.

[134] A. Sharma and B. J. Mayer, "Phosphorylation of p130Cas initiates Rac activation and membrane ruffling," BMC Cell Biology, vol. 9, article 50, 2008.

[135] M. D. Schaller and J. T. Parsons, "pp125(FAK)-dependent tyrosine phosphorylation of paxillin creates a high-affinity binding site for Crk," Molecular and Cellular Biology, vol. 15, no. 5, pp. 2635-2645, 1995.

[136] C. E. Turner, "Paxillin and focal adhesion signalling," Nature Cell Biology, vol. 2, no. 12, pp. E231-E236, 2000.

[137] J. M. Lewis and M. A. Schwartz, "Integrins regulate the association and phosphorylation of paxillin by c- Abl," The Journal of Biological Chemistry, vol. 273, no. 23, pp. 1422514230, 1998.

[138] S. Chen, R. Wang, Q. F. Li, and D. D. Tang, "Abl knockout differentially affects p130 Crk-associated substrate, vinculin, and paxillin in blood vessels of mice," American Journal of Physiology, vol. 297, no. 2, pp. H533-H539, 2009.

[139] T. Takino, M. Tamura, H. Miyamori et al., "Tyrosine phosphorylation of the CrkII adaptor protein modulates cell migration," Journal of Cell Science, vol. 116, pp. 3145-3155, 2003.

[140] R. L. Klemke, J. Leng, R. Molander, P. C. Brooks, K. Vuori, and D. A. Cheresh, "CAS/Crk coupling serves as a "molecular switch" for induction of cell migration," Journal of Cell Biology, vol. 140, pp. 961-972, 1998.

[141] K. H. Kain and R. L. Klemke, "Inhibition of cell migration by Abl family tyrosine kinases through uncoupling of Crk-CAS complexes," The Journal of Biological Chemistry, vol. 276, no. 19, pp. 16185-16192, 2001.

[142] H. Hu, J. M. Bliss, Y. Wang, and J. Colicelli, "RIN1 is an ABL tyrosine kinase activator and a regulator of epithelialcell adhesion and migration," Current Biology, vol. 15, no. 9, pp. 815-823, 2005. 

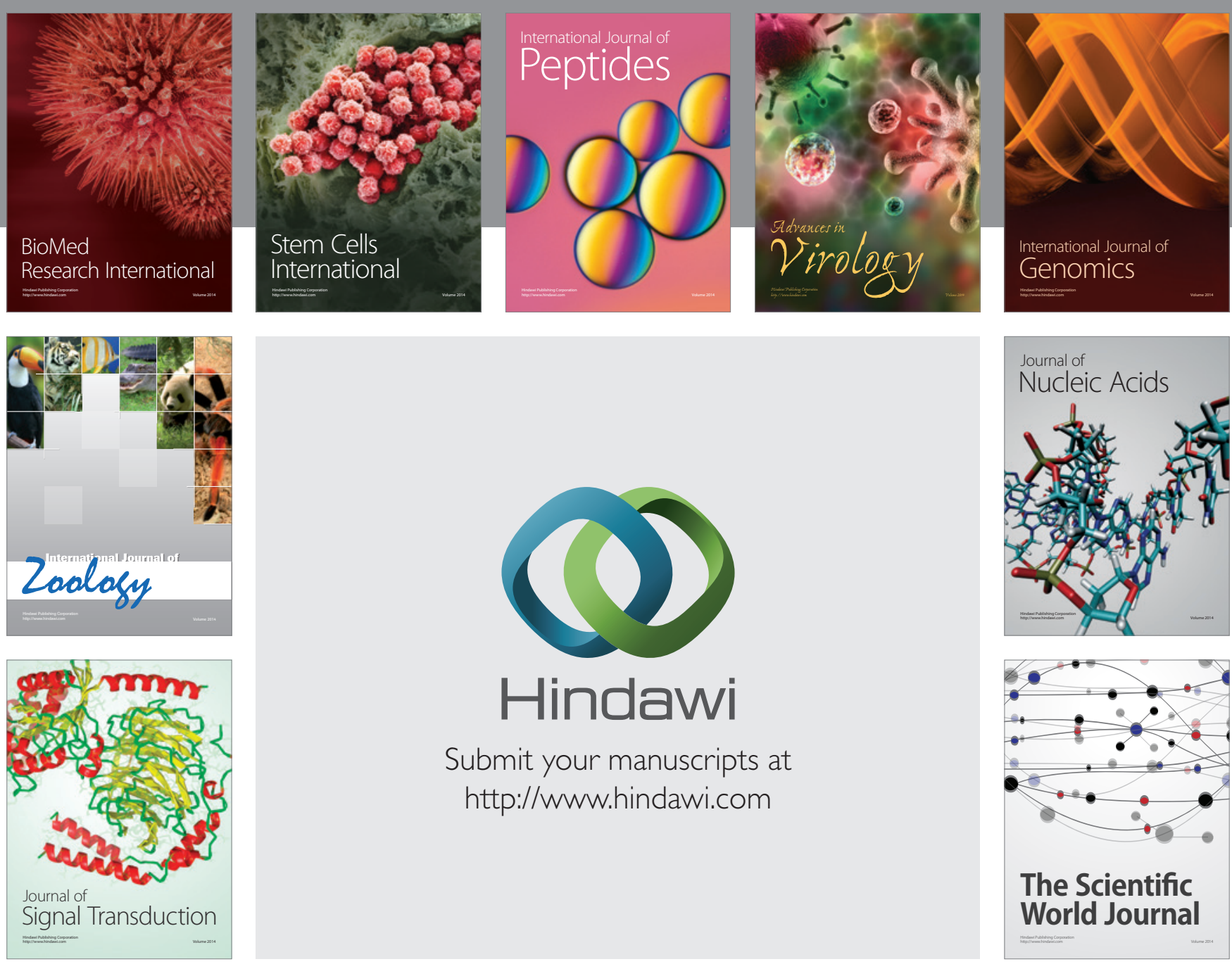

Submit your manuscripts at

http://www.hindawi.com
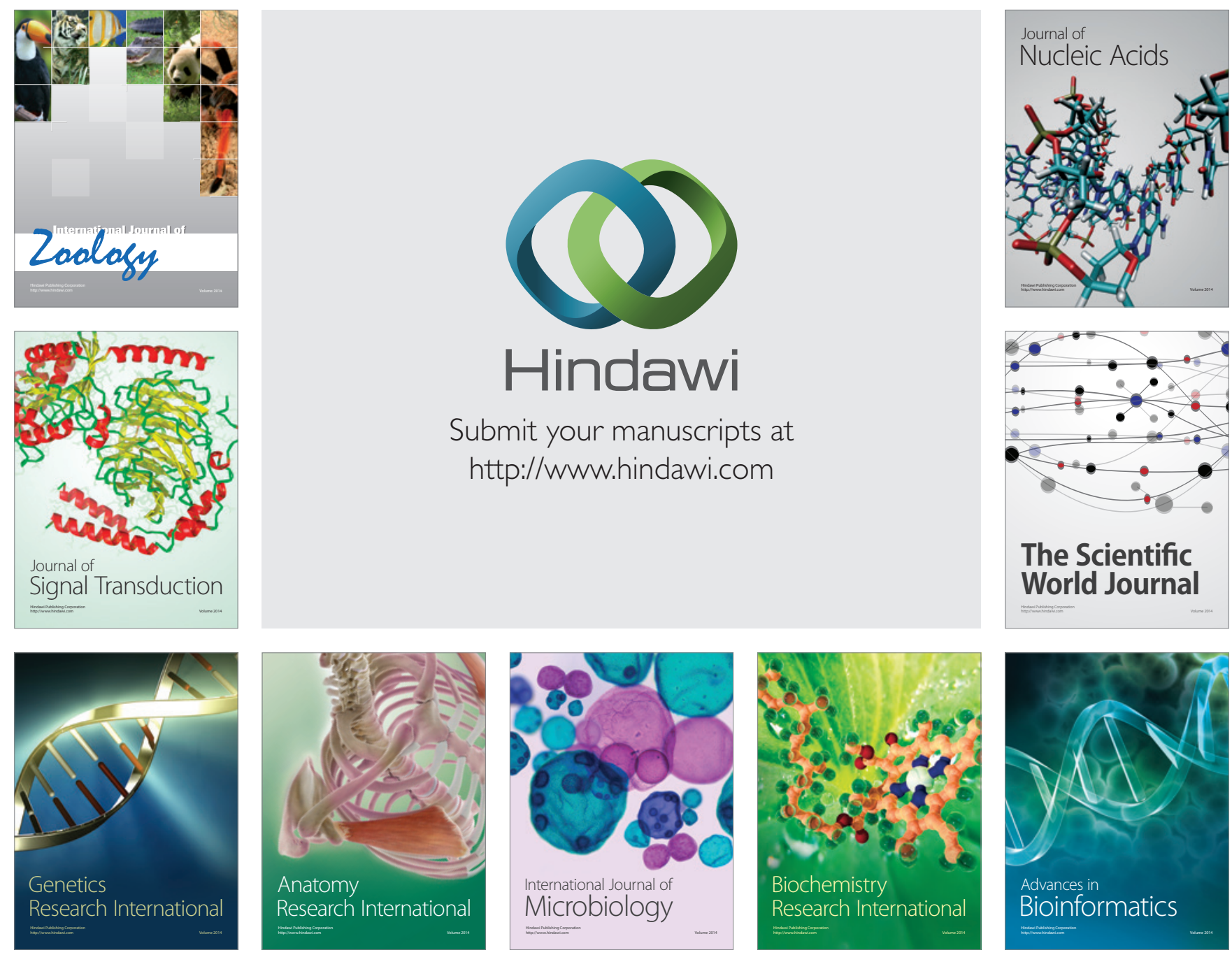

The Scientific World Journal
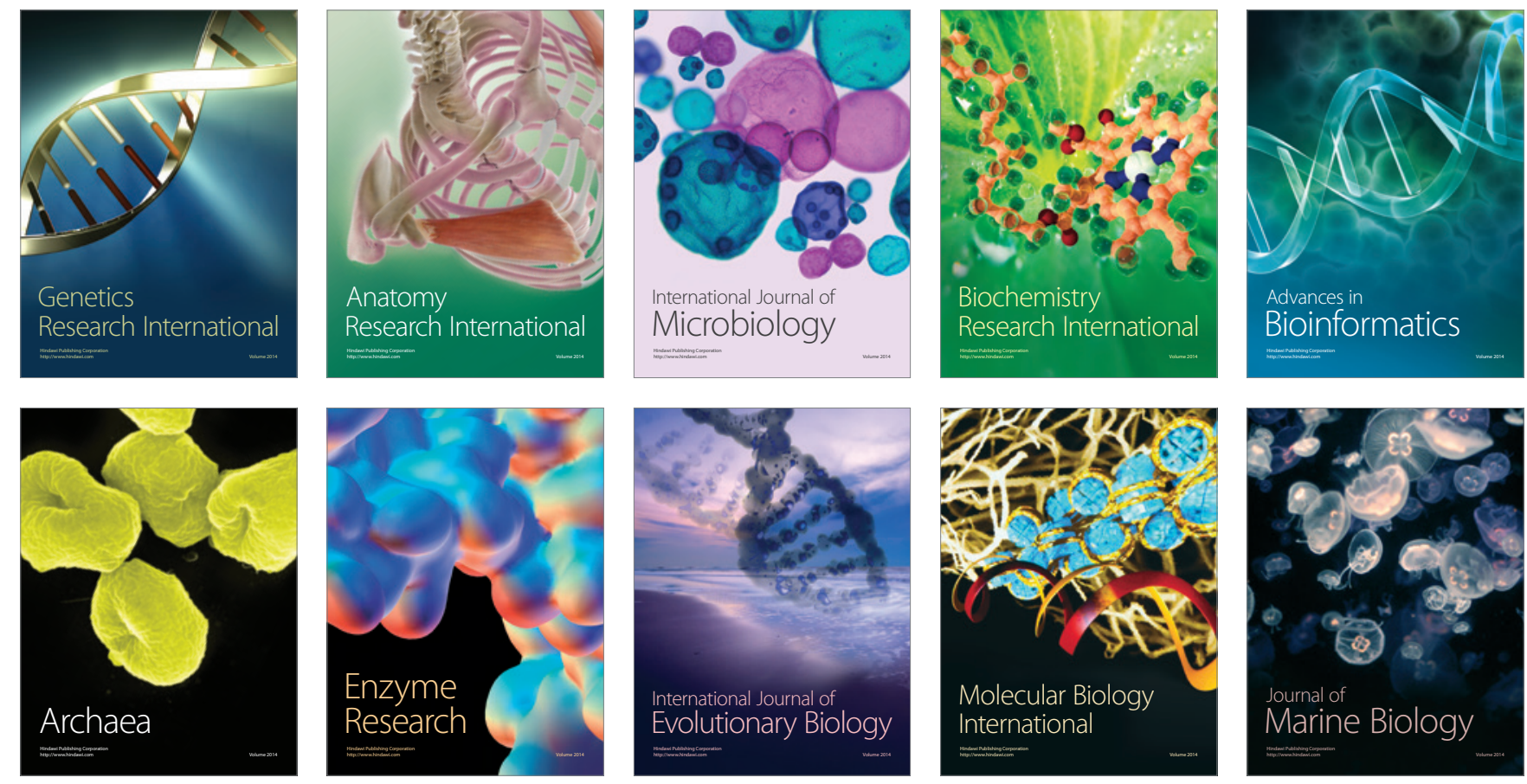